\title{
Tinnitus and equilibrium disorders in COVID-19 patients: preliminary results
}

\author{
Pasquale Viola ${ }^{1}$ Massimo Ralli ${ }^{2}$. Davide Pisani ${ }^{1}$ - Donatella Malanga ${ }^{3,4} \cdot$ Domenico Sculco $^{1} \cdot$ Luigi Messina $^{1}$. \\ Carla Laria ${ }^{5}$. Teodoro Aragona $^{6}$ - Gianluca Leopardi ${ }^{7}$. Francesco Ursini ${ }^{8,9} \cdot$ Alfonso Scarpa $^{10}$. Davide Topazio ${ }^{11}$. \\ Antonia Cama ${ }^{12}$. Viviana Vespertini ${ }^{13} \cdot$ Francesco Quintieri $^{13} \cdot$ Lucio Cosco $^{13} \cdot$ Elio Maria Cunsolo ${ }^{14}$. \\ Giuseppe Chiarella ${ }^{1}$
}

Received: 26 August 2020 / Accepted: 13 October 2020 / Published online: 23 October 2020

(c) Springer-Verlag GmbH Germany, part of Springer Nature 2020

\begin{abstract}
Purpose Tinnitus and equilibrium disorders such as dizziness and vertigo have been reported by patients with COVID-19; however, they have been rarely investigated. The aim of this study was to study the prevalence of subjective tinnitus and dizziness in a sample of COVID-19 patients using an online 10-item close-ended questionnaire.

Methods A multicentric study that included 15 Italian hospitals in different regions was conducted using an online 10-item close-ended questionnaire developed to identify the presence of tinnitus and balance disorders in patients with COVID-19 between May 5 and June 10, 2020. The questionnaire was administered to 185 patients in a period of $>30-<60$ days after diagnosis of COVID-19; responses were recorded in an online Excel spreadsheet. The questionnaire was composed of three sections: (1) demographic information; (2) presence and characteristics of tinnitus and dizziness after COVID-19 diagnosis; (3) possible association with migraine.

Results Thirty-four patients (18.4\%) reported equilibrium disorders after COVID-19 diagnosis. Of these, 32 patients reported dizziness (94.1\%) and 2 (5.9\%) reported acute vertigo attacks. Forty-three patients (23.2\%) reported tinnitus; 14 (7.6\%) reported both tinnitus and equilibrium disorders.

Conclusion This study suggests that the presence of subjective otoneurological symptoms such as tinnitus and balance disorders can affect COVID-19 patients; further studies are necessary to investigate the prevalence and pathophysiological mechanisms underlying these subjective symptoms in COVID-19 patients.
\end{abstract}

Keywords COVID-19 $\cdot$ Tinnitus $\cdot$ Vestibular disorders $\cdot$ Dizziness $\cdot$ Screening

Davide Pisani

davidepisani@gmail.com

1 Department of Experimental and Clinical Medicine, Unit of Audiology, Regional Centre for Cochlear Implants and ENT Diseases, Magna Graecia University, Catanzaro, Italy

2 Department of Sense Organs, Sapienza University of Rome, Rome, Italy

3 Laboratory of Molecular Oncology, Department of Experimental and Clinical Medicine, Magna Graecia University, Catanzaro, Italy

4 Interdepartmental Center of Services (CIS), Magna Graecia University, Catanzaro, Italy

5 Department of Neurosciences, Reproductives and Odontostomatologic Sciences, Unit of Audiology, University of Naples "Federico II", Naples, Italy

6 Unit of Otolaryngology, "Ospedali Riuniti”, Ancona, Italy
7 Unit of Otolaryngology, "S. Giuseppe Hospital”, Empoli, Firenze, Italy

8 Unit of Medicine and Rheumatology, IRCCS Istituto Ortopedico Rizzoli, Bologna", Italy

9 Department of Biomedical and Neuromotor Sciences (DIBINEM), University of Bologna, Bologna, Italy

10 Department of Medicine, Surgery and Dentistry, University of Salerno, Salerno, Italy

11 Unit of Otolaryngology, "Mazzini Hospital”, Teramo, Italy

12 Unit of Maxillofacial Surgery, "Mazzini Hospital”, Teramo, Italy

13 Unit of Infectious Diseases, "Pugliese-Ciaccio Hospital", Catanzaro, Italy

14 Unit of Otolaryngology, General Hospital of Modena and Reggio Emilia, Modena, Italy 


\section{Introduction}

Coronavirus disease 19 (COVID-19) is a pandemic caused by the severe acute respiratory syndrome coronavirus 2 (SARS-CoV-2) [1, 2]. Although the clinical features observed in COVID-19 patients mostly indicated the respiratory and circulatory systems as the primary targets of SARS-CoV-2, accumulating evidence report neurological manifestations that may affect up to $30 \%$ of COVID-19 patients [3, 4].

The neurotropic characteristics of SARS-CoV-2 are still being investigated; genome sequences were detected in the brain of affected patients, with evidence of some pathologic changes in the hypothalamus and cortex neurons [5, 6] and in the cerebrospinal fluids [7]. Several neurological manifestations such as impaired consciousness, headache, and dizziness have been reported in COVID-19 patients [8-10]; in addition, olfactory and taste alterations are common symptoms in patients affected by COVID-19 [11-15].

Even if there is growing evidence of neurological involvement of SARS-CoV-2, otoneurological subjective symptoms such as tinnitus and balance disorders have been only marginally investigated to date. The aim of this work was to investigate the prevalence of tinnitus and equilibrium disorders such as dizziness and vertigo in a sample of COVID-19 patients through an online questionnaire.

\section{Materials and methods}

A multicentric study that included 15 Italian hospitals in different regions investigated the presence of tinnitus and equilibrium disorders in COVID-19 patients; data were collected between May 5 and June 10, 2020 using an online 10-item close-ended questionnaire proposed by the authors (Table 1).

\section{Participants}

Patients with a positive nasopharyngeal swab for SARSCoV-2 (first positive swab $>30$ days $-<60$ days before questionnaire administration) were included in the study, regardless of disease severity and necessity of oxygen support during treatment. Exclusion criteria were hospitalization in Intensive Care Unit due to COVID-19, subjective hearing loss in at least one ear, an anamnestic history of acoustic trauma or prolonged noise exposure, presence of known audiological pathologies before the diagnosis of COVID-19 or previous ear surgery, psychiatric, cardiovascular or circulatory comorbidities, or concurrent or previous medical treatment with chloroquine or hydroxychloroquine for their reported ototoxic effects [16-18].

A checkbox to provide informed consent to the use of provided data was included in the questionnaire. All participants gave their informed consent to be included in the study and to the use of anonymized data provided in the responses to the questionnaire. The study was consistent with the Helsinki Declaration for human rights.

\section{Questionnaire details}

The questionnaire was designed using the Google Forms software and was administered online to patients in several Italian regions $>30-<60$ days after diagnosis of COVID19; responses were recorded in an online Excel spreadsheet. Access to the online response spreadsheet was limited to the principal investigator.

The questionnaire was composed of three parts, each one investigating a specific condition and its association with COVID-19: (1) presence and characteristics of equilibrium disorders; (2) presence and characteristics of tinnitus; (3) presence/absence of migraine. For each condition, severity was investigated using a Visual Analogue Scale (VAS)
Table 1 Online questionnaire

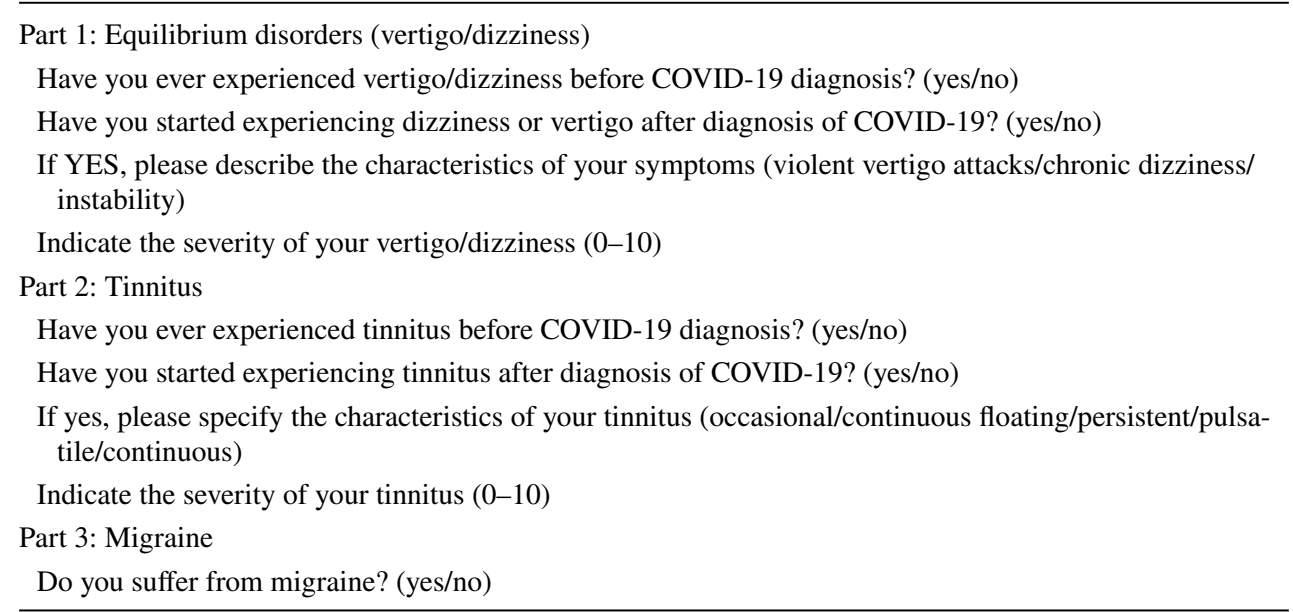


ranging from 0 (absent) to 10 (most severe); no decimals were included in the scale $[19,20]$.

\section{Statistical analysis}

Prevalence of symptoms was calculated using Statistical Packages for Social Sciences (SPSS), version 23, SPSS Inc., Chicago, IL, USA.

\section{Results}

One-hundred and eighty-five questionnaire responses from 185 patients with positive nasopharyngeal/oropharyngeal swabs for SARS-CoV-2 in a period of $>30-<60$ days from enrolment were received from May 5 to June 10, 2020. Eighty-six patients (46.5\%) were females and 99 were males (53.5\%). The mean age was $52.15(\mathrm{SD} \pm 13$; median 53$)$ with a range of $19-81$ years.

\section{Equilibrium disorders}

Thirty-four patients (18.4\%), 20 females and 14 males, reported balance disorders after COVID-19 diagnosis. Of these, thirty-two patients reported dizziness (94.1\%) and two (5.9\%) reported acute vertigo attacks [Fig. 1]. VAS score mean for equilibrium disorders was 5 .

\section{Tinnitus}

Forty-three patients (23.2\%), 15 females and 28 males, reported tinnitus after COVID-19 diagnosis. Tinnitus characteristics were as follows:

- $17 / 43(39.5 \%)$ described their tinnitus as recurrent (comes and goes away during the day);

- $10 / 43(23.3 \%)$ as occasional (episodic, sporadic);

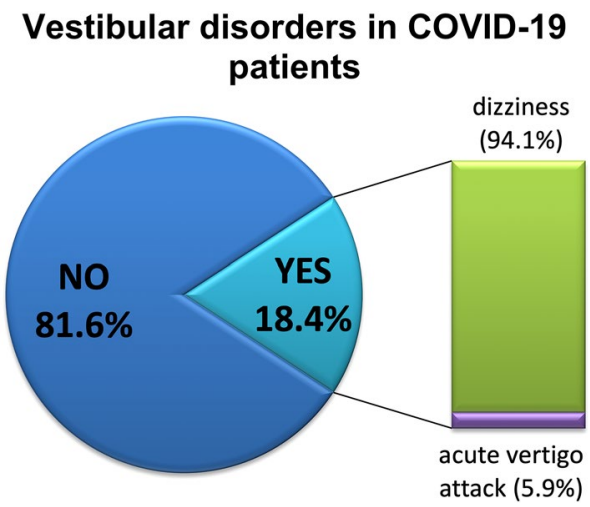

Fig. 1 Equilibrium disorders in our sample after COVID-19 diagnosis
- $7 / 43(16.3 \%)$ as continuous floating (continuous with intensity changes throughout the day);

- $4 / 43(9.3 \%)$ as persistent (always present, day and night);

- $3 / 43(7.0 \%)$ as pulsatile (synchronous with heartbeat);

- $2 / 43$ (4.6\%) as continuous (always present with the same intensity, making it difficult to fall asleep) [Fig. 2]. VAS score mean for tinnitus was 5 .

Fourteen patients (7.6\%) reported both tinnitus and balance disorders after COVID-19 diagnosis corresponding to $32.6 \%$ of the patients with tinnitus (14/43) and $41.2 \%$ of the patients with vestibular disorders (14/34).

\section{Association between otoneurological disorders and migraine}

Migraine was present in 57 patients (30.8\%). Eleven (5.9\%) patients with tinnitus diagnosis were also affected by migraine, corresponding to $25.6 \%$ of all patients with tinnitus following COVID-19 diagnosis (11/43).

Thirteen $(7.0 \%)$ patients with equilibrium disorders were also affected by migraine, corresponding to $38.2 \%$ of all patients with dizziness following COVID-19 diagnosis (13/34).

Five (2.7\%) patients with both tinnitus and balance disorders after COVID-19 diagnosis were also affected by migraine.

\section{Discussion}

Some viral infections are known to cause hearing loss, most of them typically damaging inner ear cells [21]; however, some viruses can also affect the auditory brainstem [22].

Coronavirus-related otoneurological symptoms, such as tinnitus and balance disorders, have been described so far

\section{Tinnitus in COVID-19 patients}

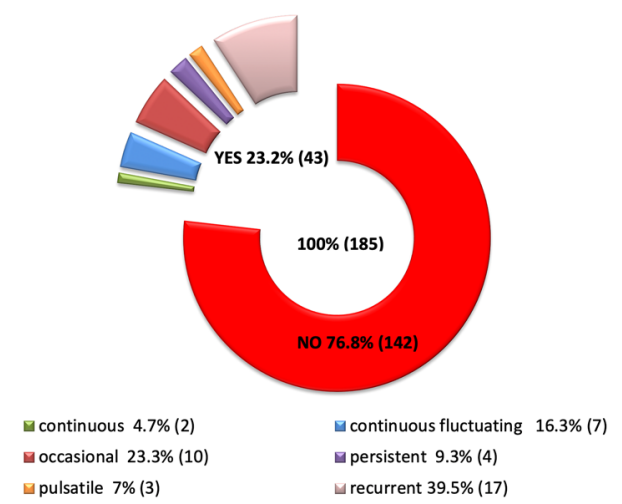

Fig. 2 Tinnitus in our sample after COVID-19 diagnosis 
[10, 23-29], as neurotrophic and neuroinvasive capabilities are typical of some coronaviruses [30]. Previous studies on other coronavirus infections showed a brain involvement, focusing attention on the possible neuro-auditory impairment following this infection [31,32]. The effects of SARS$\mathrm{CoV}-2$ on the neuronal tissue could be due to a direct infection of the central nervous system or related to a vascular damage caused by vasculitis or vasculopathy, similarly to the mechanism described for varicella zoster virus (VZV) and human immunodeficiency virus (HIV) [31, 32]. The latter could be supported by the evidence that COVID-19 patients present direct signs of hypercoagulability [33].

Hearing alterations and balance disorders can be dependent on vascular damage because the inner ear structures are particularly susceptible to ischemia due to their characteristics of terminal vasculature and high-energy requirement. Both primary and secondary vasculitis are commonly associated to audiovestibular symptoms, and primary cardiovascular disease can presents episodes of dizziness [34, 35]. Several viral infections, such as hepatitis B and hepatitis C, can be associated with vasculitis and published evidence indicates that in COVID-19 vasculitis is one of the clinical manifestation [36]. Additionally, benign paroxysmal positional vertigo has been clinically reported in COVID-19 patients, although data have not been published yet. It could be hypothesized that prolonged hospitalization and bed rest may be responsible for otolith detachment.

Despite the growing amount of scientific literature on COVID-19, studies that correlate audiovestibular symptoms to SARS-CoV-2 infection are still limited and further investigation is necessary for a better estimate of their incidence [10, 23-29]. Furthermore, the incidence of audiovestibular symptoms among patients infected with other types of coronavirus (i.e., MERS and SARS) is debated [28].

The reported prevalence of audiovestibular symptoms in COVID-19 patients is very low. It is still unclear if this indicates that these symptoms are rare or if the attention of the researchers was more focused on potentially life-threatening symptoms. In the medical literature, tinnitus and balance disorder in COVID-19 patients have been reported in a few studies without identifying common clinical characteristics. Moreover, these reports do not describe in details the relationship with COVID-19 therapies, particularly with chloroquine or hydroxychloroquine, that are well-known causes of inner ear damage [16-18, 37]. Our results, although preliminary, suggest that subjective otoneurological symptoms such as tinnitus and balance disorders may be present in a significant percentage of COVID-19 patients, and should, therefore, be further investigated. It should be taken into account the role of the central nervous system in the onset of investigated symptoms, and especially for equilibrium disorders for which it is impossible to discriminate through our questionnaire the peripheral or central origin.

\section{Limits of this study}

This preliminary study presents several limitations that should be considered. The first is the absence of COVID19 severity evaluation among patients included in the study. Therefore, the severity of the disease cannot be correlated to the presence of the investigated symptoms, as well as the effects of oxygen therapy on inner ear circulation that may be present in patients that underwent this type of support during treatment. The second is the absence of clinical evaluation of these patients (otoscopy, audiovestibular examination); however, the study investigates specifically the newly onset of these symptoms and exclude patients with pre-existing audiovestibular conditions. The third is that the study has been designed as an online reporting tool of subjective symptoms; such reporting may have been influenced by other factors that have not been investigated such as the psychological status of the patient.

\section{Conclusion}

Based on the preliminary results of this study, it could be hypothesized that subjective otoneurological symptoms such as tinnitus and balance disorders may be present in COVID19 patients free from possible bias introduced by pharmacological treatments. Further studies on larger samples are necessary to investigate the pathophysiological mechanisms that underlie the presence of these symptoms in SARS-CoV-2 infection and the persistence of these symptoms over time and their possible transformation into chronic conditions.

Funding The authors declare that they have no sources of funding.

\section{Compliance with ethical standards}

Conflict of interest The authors declare that they have no conflict of interest.

Human and animals rights Not applicable.

Informed consent A checkbox to provide informed consent to the use of provided data was included in the questionnaire. All participants gave their informed consent to the use of anonymized data provided in the responses to the questionnaire.

\section{References}

1. Gentile I, Abenavoli L (2020) COVID-19: perspectives on the potential novel global threat. Rev Recent Clin Trials. https://doi. org/10.2174/1574887115999200228100745 
2. Tian S, Hu N, Lou J, Chen K, Kang X, Xiang Z, Chen H, Wang D, Liu N, Liu D, Chen G, Zhang Y, Li D, Li J, Lian H, Niu S, Zhang L, Zhang J (2020) Characteristics of COVID-19 infection in Beijing. J Infect 80(4):401-406. https://doi.org/10.1016/j. jinf.2020.02.018

3. Ahmad I, Rathore FA (2020) Neurological manifestations and complications of COVID-19: A literature review. J ClinNeurosci 77:8-12. https://doi.org/10.1016/j.jocn.2020.05.017

4. Mao L, Jin H, Wang M, Hu Y, Chen S, He Q, Chang J, Hong C, Zhou Y, Wang D, Miao X, Li Y, Hu B (2020) Neurologic manifestations of hospitalized patients with coronavirus disease 2019 in Wuhan. JAMA Neurol, China. https://doi.org/10.1001/jaman eurol.2020.1127

5. Paniz-Mondolfi A, Bryce C, Grimes Z, Gordon RE, Reidy J, Lednicky J, Sordillo EM, Fowkes M (2020) Central nervous system involvement by severe acute respiratory syndrome coronavirus-2 (SARS-CoV-2). J Med Virol 92(7):699-702. https://doi. org/10.1002/jmv.25915

6. Gu J, Gong E, Zhang B, Zheng J, Gao Z, Zhong Y, Zou W, Zhan J, Wang S, Xie Z, Zhuang H, Wu B, Zhong H, Shao H, Fang W, Gao D, Pei F, Li X, He Z, Xu D, Shi X, Anderson VM, Leong AS (2005) Multiple organ infection and the pathogenesis of SARS. J Exp Med 202(3):415-424. https://doi.org/10.1084/jem.20050828

7. Huang YH, Jiang D, Huang JT (2020) SARS-CoV-2 detected in cerebrospinal fluid by PCR in a case of COVID-19 encephalitis. Brain BehavImmun 87:149. https://doi.org/10.1016/j. bbi.2020.05.012

8. Wu Y, Xu X, Yang L, Liu C, Yang C (2020) Nervous system damage after COVID-19 infection: presence or absence? Brain BehavImmun 87:55. https://doi.org/10.1016/j.bbi.2020.04.043

9. Moriguchi T, Harii N, Goto J, Harada D, Sugawara H, Takamino J, Ueno M, Sakata H, Kondo K, Myose N, Nakao A, Takeda M, Haro H, Inoue O, Suzuki-Inoue K, Kubokawa K, Ogihara S, Sasaki T, Kinouchi H, Kojin H, Ito M, Onishi H, Shimizu T, Sasaki Y, Enomoto N, Ishihara H, Furuya S, Yamamoto T, Shimada $S$ (2020) A first case of meningitis/encephalitis associated with SARS-Coronavirus-2. Int J Infect Dis 94:55-58. https://doi. org/10.1016/j.ijid.2020.03.062

10. OzcelikKorkmaz M, Egilmez OK, Ozcelik MA, Guven M (2020) Otolaryngological manifestations of hospitalised patients with confirmed COVID-19 infection. Eur Arch Otorhinolaryngol. https ://doi.org/10.1007/s00405-020-06396-8

11. Ralli M, Stadio A, Greco A, Vincentiis M, Polimeni A (2020) Defining the burden of olfactory dysfunction in COVID-19 patients. Eur Rev Med PharmacolSci 24(7):3440-3441. https:// doi.org/10.26355/eurrev_202004_20797

12. Lechien JR, Chiesa-Estomba CM, De Siati DR, Horoi M, Le Bon SD, Rodriguez A, Dequanter D, Blecic S, El Afia F, Distinguin L, Chekkoury-Idrissi Y, Hans S, Delgado IL, Calvo-Henriquez C, Lavigne P, Falanga C, Barillari MR, Cammaroto G, Khalife M, Leich P, Souchay C, Rossi C, Journe F, Hsieh J, Edjlali M, Carlier R, Ris L, Lovato A, De Filippis C, Coppee F, Fakhry N, Ayad T, Saussez S (2020) Olfactory and gustatory dysfunctions as a clinical presentation of mild-to-moderate forms of the coronavirus disease (COVID-19): a multicenter European study. Eur Arch Otorhinolaryngol 277(8):2251-2261. https://doi.org/10.1007/ s00405-020-05965-1

13. Giacomelli A, Pezzati L, Conti F, Bernacchia D, Siano M, Oreni L, Rusconi S, Gervasoni C, Ridolfo AL, Rizzardini G, Antinori S, Galli M (2020) Self-reported olfactory and taste disorders in patients with severe acute respiratory coronavirus 2 infection: a cross-sectional study. Clin Infect Dis 71(15):889-890. https://doi. org/10.1093/cid/ciaa330

14. Spadera L, Viola P, Pisani D, Scarpa A, Malanga D, Sorrentino G, Madini E, Laria C, Aragona T, Leopardi G, Maggiore G, Ciriolo M, Boccuto L, Pizzolato R, Abenavoli L, Cassandro
C, Ralli M, Cassandro E, Chiarella G (2020) Sudden olfactory loss as an early marker of COVID-19: a nationwide Italian survey. Eur Arch Otorhinolaryngol. https://doi.org/10.1007/s0040 5-020-06252-9

15. Chiarella G, Pizzolato R, Malanga D, Pisani D, Abenavoli L, Viola P (2020) Prevention of COVID-19 infection in the medical population: a possible help from anosmia? Rev Recent Clin Trials. https://doi.org/10.2174/1574887115666200603152637

16. Altissimi G, Colizza A, Cianfrone G, Vincentiis M, Greco A, Taurone S, Musacchio A, Ciofalo A, Turchetta R, Angeletti D, Ralli M (2020) Drugs inducing hearing loss, tinnitus, dizziness and vertigo: an updated guide. Eur Rev Med PharmacolSci 24(15):7946-7952. https://doi.org/10.26355/eurrev_20200 $8 \_22477$

17. Prayuenyong P, Kasbekar AV, Baguley DM (2020) Clinical Implications of Chloroquine and Hydroxychloroquine Ototoxicity for COVID-19 treatment: a mini-review. Front Public Health 8:252. https://doi.org/10.3389/fpubh.2020.00252

18. Ralli M, Lobarinas E, Fetoni AR, Stolzberg D, Paludetti G, Salvi $R$ (2010) Comparison of salicylate- and quinine-induced tinnitus in rats: development, time course, and evaluation of audiologic correlates. OtolNeurotol 31(5):823-831. https://doi.org/10.1097/ MAO.0b013e3181de4662

19. Raj-Koziak D, Gos E, Swierniak W, Rajchel JJ, Karpiesz L, Niedzialek I, Wlodarczyk E, Skarzynski H, Skarzynski PH (2018) Visual analogue scales as a tool for initial assessment of tinnitus severity: psychometric evaluation in a clinical population. AudiolNeurootol 23(4):229-237. https://doi.org/10.1159/000494021

20. Dannenbaum E, Chilingaryan G, Fung J (2011) Visual vertigo analogue scale: an assessment questionnaire for visual vertigo. J Vestib Res 21(3):153-159. https://doi.org/10.3233/ VES-2011-0412

21. Cohen BE, Durstenfeld A, Roehm PC (2014) Viral causes of hearing loss: a review for hearing health professionals. Trends Hear. https://doi.org/10.1177/2331216514541361

22. Abramovich S, Prasher DK (1986) Electrocochleography and brain-stem potentials in Ramsay Hunt syndrome. Arch Otolaryngol Head Neck Surg 112(9):925-928. https://doi.org/10.1001/ archotol.1986.03780090021002

23. Elibol E (2020) Otolaryngological symptoms in COVID-19. Eur Arch Otorhinolaryngol. https://doi.org/10.1007/s00405-02006319-7

24. Malayala SV, Raza A (2020) A Case of COVID-19-Induced Vestibular Neuritis. Cureus 12(6):e8918. https://doi.org/10.7759/ cureus. 8918

25. Munro KJ, Uus K, Almufarrij I, Chaudhuri N, Yioe V (2020) Persistent self-reported changes in hearing and tinnitus in posthospitalisation COVID-19 cases. Int J Audiol 1:1-2

26. Fiani B, Covarrubias C, Desai A, Sekhon M, Jarrah R (2020) A Contemporary review of neurological sequelae of COVID-19. Front Neurol 11:640. https://doi.org/10.3389/fneur.2020.00640

27. Freni F, Meduri A, Gazia F, Nicastro V, Galletti C, Aragona P, Galletti C, Galletti B, Galletti F (2020) Symptomatology in head and neck district in coronavirus disease (COVID-19): a possible neuroinvasive action of SARS-CoV-2. Am J Otolaryngol 41(5):102612. https://doi.org/10.1016/j.amjoto.2020.102612

28. Almufarrij I, Uus K, Munro KJ (2020) Does coronavirus affect the audio-vestibular system? A rapid systematic review. Int J Audiol 59(7):487-491. https://doi.org/10.1080/14992027.2020.1776406

29. Karimi-Galougahi M, Naeini AS, Raad N, Mikaniki N, Ghorbani J (2020) Vertigo and hearing loss during the COVID-19 pandemic - is there an association? ActaOtorhinolaryngolItal. https://doi. org/10.14639/0392-100X-N0820

30. Sriwijitalai W, Wiwanitkit V (2020) Hearing loss and COVID-19: a note. Am J Otolaryngol 41(3):102473. https://doi.org/10.1016/j. amjoto.2020.102473 
31. Chetty R, Batitang S, Nair R (2000) Large artery vasculopathy in HIV-positive patients: another vasculitic enigma. Hum Pathol 31(3):374-379. https://doi.org/10.1016/s0046-8177(00)80253-1

32. Gilden DH, Kleinschmidt-DeMasters BK, Wellish M, HedleyWhyte ET, Rentier B, Mahalingam R (1996) Varicella zoster virus, a cause of waxing and waning vasculitis: the New England Journal of Medicine case 5-1995 revisited. Neurology 47(6):1441-1446. https://doi.org/10.1212/wnl.47.6.1441

33. Panigada M, Bottino N, Tagliabue $\mathrm{P}$, Grasselli G, Novembrino C, Chantarangkul V, Pesenti A, Peyvandi F, Tripodi A (2020) Hypercoagulability of COVID-19 patients in intensive care unit: a report of thromboelastography findings and other parameters of hemostasis. J ThrombHaemost 18(7):1738-1742. https://doi. org/10.1111/jth.14850

34. Ralli M, Campo F, Angeletti D, Minni A, Artico M, Greco A, Polimeni A, de Vincentiis M (2020) Pathophysiology and therapy of systemic vasculitides. EXCLI J 19:817-854. https://doi. org/10.17179/excli2020-1512
35. Ralli M, Di Stadio A, De Virgilio A, Croce A, de Vincentiis M (2018) Autoimmunity and otolaryngology diseases. J Immunol Res 1:2747904. https://doi.org/10.1155/2018/2747904

36. Roncati L, Ligabue G, Fabbiani L, Malagoli C, Gallo G, Lusenti B, Nasillo V, Manenti A, Maiorana A (2020) Type 3 hypersensitivity in COVID-19 vasculitis. ClinImmunol 217:108487. https:// doi.org/10.1016/j.clim.2020.108487

37 De Luca P, Scarpa A, De Bonis E, Cavaliere M, Viola P, Gioacchini MF, Ralli M, Cassandro E, Cassandro C (2020) Chloroquine and hydroxychloroquine ototoxicity; potential implications for SARS-CoV-2 treatment. A brief review of the literature. Am J Otol 8:102640. https://doi.org/10.1016/j.amjoto.2020.102640

Publisher's Note Springer Nature remains neutral with regard to jurisdictional claims in published maps and institutional affiliations. 